\title{
An Acoustic Analysis of Tone and Register in Louma Oeshi
}

\author{
Sigrid Lew \& James Gruber*
}

\begin{abstract}
This study describes the acoustic properties associated with tone and register in Louma Oeshi, a previously unstudied Akoid language of Laos. Louma Oeshi uses three tones (High, Mid, and Low) which overlap with a tense/lax register distinction to yield a six-way suprasegmental contrast. In this paper, we (1) offer a first account of the pitch and voice quality characteristics associated with each Tone-Register pair, (2) examine further the variability in glottalization strategies signaling the constricted register, and (3) explore the influence of contrastive voice quality on pitch and vice versa, particularly as a predictor of the variation in glottalization.
\end{abstract}

Keywords. tone; register; voice quality; Tibeto-Burman; Louma; Oeshi

1. Introduction. This study describes the acoustic properties associated with tone and register in Louma Oeshi (henceforth Oeshi), a previously unstudied Akoid/Hanoid language in Laos, belonging to the Southern Lolo/Ngwi subgroup of Tibeto-Burman. Like other Southern Ngwi languages, Oeshi phonology employs three tone levels (High, Mid, and Low) and an overlapping a tense/lax register distinction. In the case of Oeshi, tone and register are fully intersective such that they combine to yield a six-way suprasegmental contrast. In recent decades, the phonetic literature has shown that the boundary between what have traditionally been known as "tone" and "register" languages is often quite blurred, particularly in languages of mainland Southeast Asia (Abramson \& Luangthongkum, 2009). How a mixed tone-register prosodic system weighs or emphasizes its multiple contrasts has become an issue of great interest to both phoneticians and phonologists (Silverman 1997; Brunelle 2005; DiCanio 2009, 2010, 2012; Clements, Michaud \& Patin 2011; Gruber 2011; Esposito 2012; Kuang 2013; Yu \& Lam 2014; Brunelle \& Kirby 2016).

The complete intersection of tone and register levels in Oeshi (Lax and Tense register co-occur with each Low, Mid and High tone) indicates that the qualities are phonologically independent in the sense of Kuang (2013), but raises questions about their phonetic interaction. In addition to providing a first account of Oeshi tonal phonetics, this paper explores how voice quality settings affect pitch across the tone-register combinations, and vice versa. The preliminary data presented here suggests that pitch and voice quality are mostly independent in their phonetic production as well. That is, Oeshi speakers manipulate pitch or voice quality characteristics without great influence on the other property. There is, however, a substantial exception to this observation -- High Tense tone-register words, which are noteworthy for a variety of reasons.

The paper proceeds as follows. We first describe the relationship of Oeshi to other regional languages with similar, but importantly different, complex tone-register systems (§2). After explaining our experimental methods and analytic techniques (§3), we provide the findings $(\$ 4)$ for the two most successful acoustic correlates of the six-way prosodic contrasts: $\mathrm{FO}$, the fundamental frequency of the acoustic signal (tone) and $* \mathrm{H} 1-\mathrm{H} 2$, the

\footnotetext{
* Dr. Sigrid Lew, Payap University (sigrid 1@payap.ac.th) \& Dr. James Gruber, Reed College (jamesfgruber@gmail.com).
} 
amplitude difference in low-frequency spectral information captured by the first two voice harmonics. In $\S 5$, we discuss these findings, and the lack of findings for other possible acoustic measures, in the context of the study's methods and the multiple surface instantiations of phonemic register in Oeshi.

2. Background. Bradley (1996) lists the Lou Ma among other Akoid subgroups in a survey of Southern Loloish languages in the Tibeto-Burman family. No mention is made of linguistic properties, but it is presented as a variety or a close relation of Akha. This is the sole mention of a Louma language that we are aware of in a published document. Manuscripts by Gregerson, Gregerson \& Vitikainen (2011) and Potter (2012) explore phonological features of up to three possible Louma varieties, one of which is Oeshi. Gregerson et al. isolate the Oeshi variety spoken in Moutern village from the other Oeshi varieties, and Potter's (2012) description lists three distinct clanlects found in Lao PDR: Oeshi, Meutoe, and Pala. Speakers of each clanlect regard themselves as Louma and the three varieties are reported to have 95\% lexical similarity (Potter 2012).

Gregerson et al. (2011) argue that Oeshi (which he labels ' $R$ shi') is closely related (though distinct) with Akha and Hani, forming a separate branch of the Southern Lolo Akoid tree. Evidence for his classification comes from wordlists compiled for Akha, Hani and Oeshi which reveal that all three preserve a proto *a, where other Southern Lolo languages developed a rounded back vowel (Hansson 1989). However, in many cases Akha and Hani have fricatives where Oeshi has plosives, and plosives where Oeshi has fricatives. Furthermore, the Oeshi wordlist attests several compounds in the place of Akha and Hani monosyllable forms. Despite multiple cognate similarities, Louma speakers do not understand Akha, as reported by the Akha speaker who collected the ethnological data in Potter's (2012) study. Conversely, Akha speakers do not consider Louma speakers as Akha, either, and call them Louma.

According to our primary consultant, a bilingual Oeshi-Lao speaker, there are only two Louma varieties: Louma proper and Louma Oeshi. Both have several dialects, distinguished most clearly by sentence-final particles, some phonological and a few lexical differences. The village name Moutern in fact refers to yet another mutually unintelligible language whose speakers once inhabited the area but now reside further south in the province, having departed when Louma speakers settled the region. Potter's other alleged clanlect "Pala"seems to not be a separate variety, so much as an antiquated term for both Louma and Oeshi.

Geographically, the Louma proper varieties are potentially under pressure from $\mathrm{Lao}$, the national language, and $\mathrm{Khmu}$, the regional prestige language. In relatively more urban areas, Louma speakers are mostly bi- or multilingual. For these reasons, we sought to record and analyze Oeshi speakers, the majority of whom are rural village inhabitants far more likely to be monolingual or have very limited exposure to Lao or Khmu. While the preliminary data given in this paper includes two speakers, one of whom is relatively fluent in Lao, additional speakers (both male and female) recorded for a larger ongoing project are primarily monolingual Oeshi.

The close relationship of Oeshi to Akha and Hani is noteworthy because the two employ similar mixed tone and register systems, but with a key difference. Both Akha (Katsura 1970, Lewis 1973, Bradley 1977a) and Hani (Kuang 2013) have 3 tones: a High, Mid and Low; and two registers, a more open modal or lax phonation is contrasted with a more constricted, laryngealized register. The two intersect, but there is a distributional restriction in that the High tone only co-occurs with the more open register. So a $3 \times 2$ 
contrast yields 5 possible combinations, because a High Constricted combination is not permitted.

Kuang notes that, although they are not phonologically independent, phonation and pitch in the Yi languages are phonetically independent. Her study found that speakers of Southern Yi, Bo, and Hani produce tones such that "phonation can be kept constant while changing pitch, and pitch can be kept constant while changing phonation (2013: 42)."

Lewis (1973) and Hansson (2003) note that the High Tense combination may occur in Akha, though neither provides examples and both state that it is very rare and primarily restricted to place and personal names. The High Tense category similar seems to bear a low functional load for Oeshi. The speakers confirmed the existence of a High Tense tone and though early fieldwork sessions explicitly aimed for eliciting lexical items, only four High Tense lexical items could be identified for a 100-item wordlist. One confound seems to be that tone and phonation can bear grammatical functions (as in Akha, per Hansson 2003) and thus words which may at times be produced as High Tense are in fact underlyingly Mid Tense or High Lax. Frequently, a final glottal stop marked citation forms for some verbs and nouns, though this phenomenon does not occur across all lexemes or particular word types and requires further investigation.

3. Methodology. The study seeks to provide a first account of the phonetic characteristics associated with each Oeshi tone-register pair, focusing on the interaction of pitch and voice quality. Measures of pitch and voice quality were taken dynamically over the course of the syllable rime and hierarchical regression modeling was used to test the effect of tone and register setting on each acoustic correlate.

3.1 PARTICIPANTS. Data is drawn from recordings with two male speakers in Mueang Mai District, Phongsaly Province, Lao PDR. In total, four male speakers participated, but lessthan-ideal recording conditions (see §3.3) limit us to presenting data from the two individuals who spoke loudly and clearly enough for suitable analysis. Speaker A is from Moutern [mutôn] village and was 22 years old at the time of recording. He has a relatively high level of education (one year of secondary school) and is a proficient Lao speaker. Speaker B hails from a neighboring village and was 19 years old for the recording. He is a mostly monolingual Oeshi speaker, having attended 3 years of school. He can comprehend, read and write Lao with some effort, but generally avoids doing so in his day-to-day life.

Village life is monolingual in Oeshi, with Lao and Khmu used by speakers who frequently leave the village. All Louma children are monolingual, as are their mothers. While children receive education in Lao, most drop out before developing any Lao proficiency.

3.2 MATERIALS. Each speaker repeated a 30 item word list that constituted roughly 5 near-minimal sets of the six-way contrast (see word list in Table 1 below). Each word was uttered twice in isolation and in two carrier phrases, one which positioned the keyword between two lax mid-tones and another which used the keyword sentenceinitially before a tense low-toned word. In the analysis, these three contexts are referred to as (1) Phrase-medial, (2) Phrase-initial, and (3) Citation form. Only the first citation form utterance was analyzed with extra repetitions discarded. 
(1) Phrase-medial carrier sentence

$$
\begin{aligned}
& \text { nó __ gu-ßé? ya mà kjàlá-ja? } \\
& \text { 2SG ( ) say-REALIS 1SG NEG hear-PAST } \\
& \text { "I didn't hear you saying ----." }
\end{aligned}
$$

(2) Phrase-initial carrier sentence

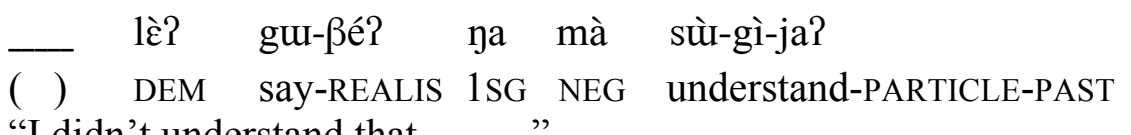

\begin{tabular}{|c|c|c|c|c|c|}
\hline jàné & LL & 'own child' & kijà? & $\mathrm{LT}$ & 'bird' \\
\hline dja & ML & 'got it!' & ja? & MT & 'sweep' \\
\hline $\mathrm{t}^{\mathrm{h}}$ ù̀já & HL & 'hundred' & já? & HT & 'here' \\
\hline $\mathrm{t}^{\mathrm{h}} \grave{ø}^{\mathrm{h}} \mathrm{á}$ & LL & 'to spit' & $\mathrm{t}^{\mathrm{h}} \grave{\text { ? }}$ & $\mathrm{LT}$ & 'to pound' \\
\hline $\mathrm{p}^{\mathrm{h}} \mathrm{itc}^{\mathrm{h}}{ }_{\varnothing}$ & $\mathrm{ML}$ & 'mongoose' & nák ${ }^{\mathrm{h}}$ ? & $\mathrm{MT}$ & 'behind' \\
\hline $\mathrm{t}^{\mathrm{h}} \varnothing$ & $\mathrm{HL}$ & 'kick with foot' & $\mathrm{t}^{\mathrm{h}} \varnothing ́ ?$ & HT & 'over there' \\
\hline $\mathrm{t}^{\mathrm{h}}$ ùubà & LL & 'thousand' & bà? & $\mathrm{LT}$ & 'carry on shoulder' \\
\hline bàba & ML & 'cheek' & $\mathrm{t}^{\mathrm{h}}$ ùuba? & $\mathrm{MT}$ & 'portion' \\
\hline abá & $\mathrm{HL}$ & 'grandfather' & - & $\mathrm{HT}$ & - \\
\hline gégù & LL & 'mango' & gù? & LT & 'to embroider' \\
\hline kujà & ML & 'bowl' & gu? & $\mathrm{MT}$ & 'rice grain' \\
\hline gú & $\mathrm{HL}$ & 'shout out' & - & HT & - \\
\hline nà & LL & 'ear' & canà? & $\mathrm{LT}$ & 'lean meat, muscle' \\
\hline nàma & ML & 'deep' & càna? & MT & 'mole (skin)' \\
\hline ná & $\mathrm{HL}$ & 'hurt' & - & HT & - \\
\hline
\end{tabular}

"I didn't understand that - -----."

(3) Citation form - word spoken in isolation

Table 1. Oeshi word list

3.3 Procedure. Sessions with each speaker were conducted in an office building in Mueang Mai. Recordings were made with a Zoom H2 portable recorder with built-in microphone attached to a Sony MVR-HD1 video recorder. The recording location was problematic and the authors openly acknowledge that the resulting recording quality was compromised by overhead fluorescent lights and reverberating concrete of the building. In analysis, fundamental frequency could be determined with confidence, but measures of spectral information reflecting voice quality were potentially hindered by the poor 
recording quality.

Instructions were provided in Lao to a bilingual Lao-Oeshi interpreter. Prior to the data elicitation, subjects provided recorded verbal consent to the research procedures in Oeshi. The interpreter reviewed the wordlist with each subject prior to recording and then prompted each word/utterance in a randomized order for elicitation.

3.4. ANALYSIS. Recordings were manually segmented using Audacity and processed in Praat 5.4 (Boersma \& Weenink 2015). Decile measures of F0 and a suite of measures investigating phonation types (H1-H2, H1-A1, H1-A3, HNR, and SHR) were performed in Voicesauce (Shue et al 2011) and exported for statistical analysis by regression modeling in $\mathrm{R}$ ( $\mathrm{R}$ Core Team 2012). The variety of acoustic measures employed have become common in recent phonetic literature regarding voice quality (e.g. Esposito 2006, Khan 2012, Berkson 2013, Kirby 2014). These measures are generally of two types; (i) those which take the spectral profile of a vowel and look at aspects of it which are thought to be indicative of the glottal source vibration (spectral slope, SHR) and (ii) those which measure the amount of noise generated at the glottis (HNR, SHR).

The fixed effects of Tone (H, M, L), Register (Lax, Tense) and Frame (Initial, Medial, Citation) were tested in hierarchical linear regressions with each of the above measures as a dependent variable (DV). The individual word was included as a random effect, thereby mediating the degree to which production of a single word may influence the results. Values for each measure were tested as overall means as well as the mean at each decile point. Regression tests for each DV were initiated with a model that included each term (Tone, Register, Frame) and their interactions. Insignificant interactions and factors were step-wise pruned from the model until a final model was reached which only included significant factors.

Results of the regression tests are provided in Section 4 for the overall mean and value at the $8^{\text {th }}$ decile, i.e. a measure taken at the $4 / 5^{\text {ths }}$ point of the vowel's duration. This location is provided because it yielded the strongest statistical confirmation of a contrast between the tones, a result which reflects the importance of the vowel terminus as a locus of contrastive voice quality and pitch movement.

4. Results. Acoustic analysis reveals a reliable 3-way F0 contrast between mostly level tones and a single interaction with register such that High Tense words consistently fall in pitch. Acoustic correlates of the Tense $\sim$ Lax distinction are less clear, though the corrected $\mathrm{H} 1-\mathrm{H} 2 *$ most often captures the Oeshi tense register, particularly Low Tense forms.

Figures 1 and 2 offer representative examples of Lax and Tense syllables as produced by Speaker A in the Citation form context. Glottalization in the Tense form (Figure 2) is subtle but apparent in the uneven striations of the glottal pulses approaching the end of the vowel. In other cases, the vowel of a Tense syllable displays very few indicators of a constricted glottal state. Rather, the Tense register is manifest most prominently as glottalization of the onset or coda consonant, or even complete replacement with a final glottal stop. The nature of this variation - whether the precise phonetic realization of "tenseness" is a product of certain speakers, words, consonants or 


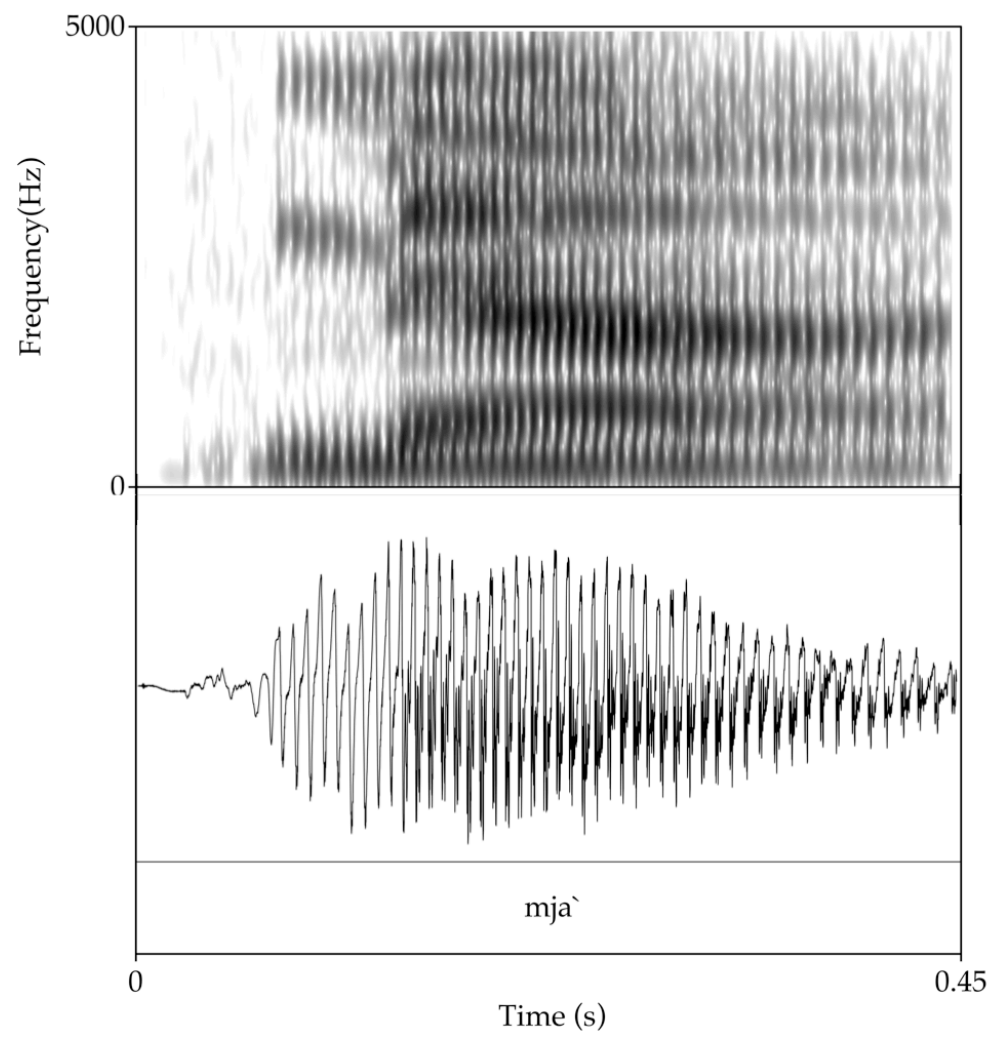

Figure 1. Low lax [mjà]

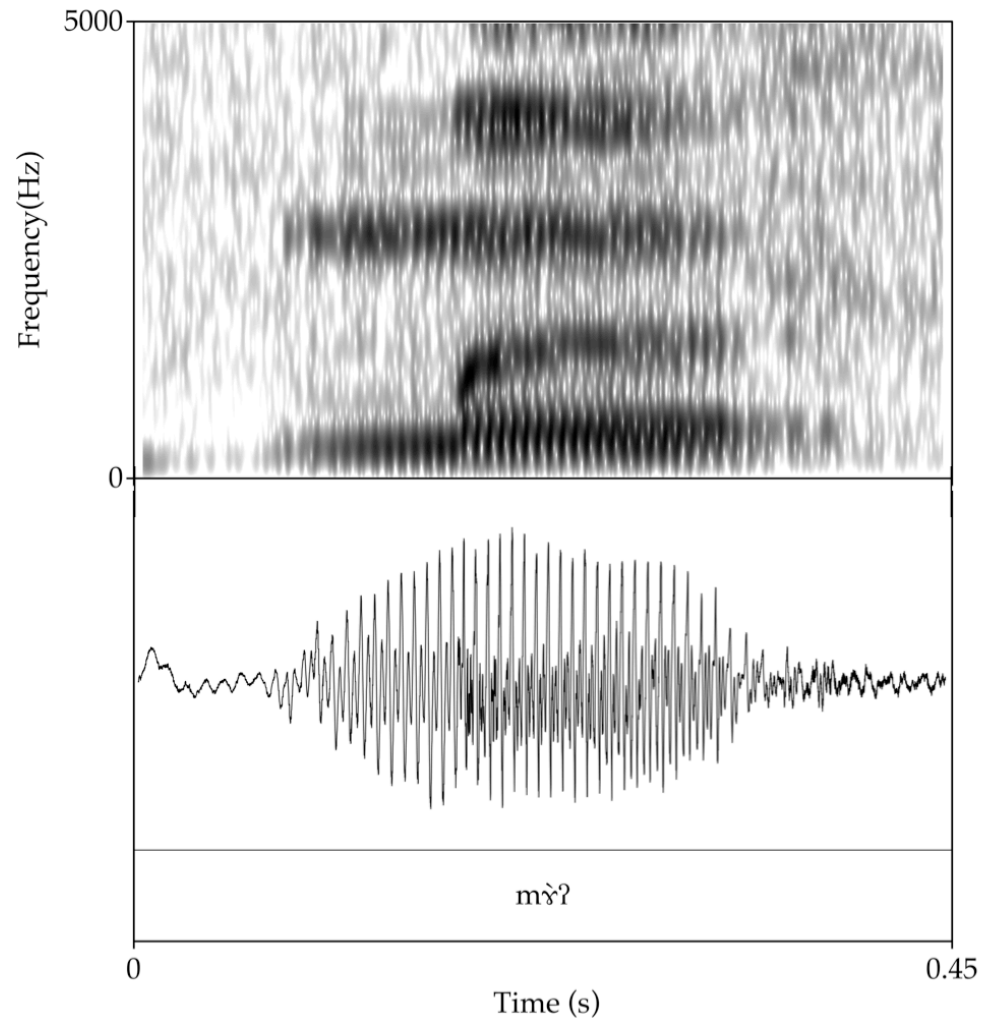

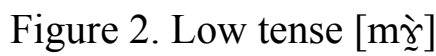


tones - is a worthwhile matter for future research but is not explored further in this paper. Comprehensive presentation of results for each relevant acoustic measure are similarly beyond the scope of the present work. In the sections below, we limit our presentation to results for $\mathrm{F} 0$ and $\mathrm{H} 1-\mathrm{H} 2 *$, and then summarize the statistical inferences reached for the array of other measures.

Differences in pitch and phonation properties between the two sentential contexts were weak to non-existent. Admittedly, the two phrases bore similarities - the phrasemedial frame sentence placed the token of interest as the second overall element in the sentence, which may offer negligible contrast from the first overall position of phraseinitial contexts. Furthermore, tokens were generally produced with a topic focus thereby imbuing the embedded tokens with a pronunciation that sometimes leans toward citationform qualities. Ultimately though, the citation form utterances proved to have distinctive influences on the form of the words under investigation, such as a distinct final glottal stop missing in the sentence-medial form.

4.2. Fundamental FREQUENCY. The mean F0 values at each time decile for each ToneRegister pair are plotted in Figure 3 (Speaker A) and Figure 4 (Speaker B). Lax register forms are represented by a solid line, while tense register means are a dashed line. Plainly, a three-way divide in pitch height is evident, but overall four distinct F0 contours emerge: a low, a mid, a high falling and high rising.

Note that there is very little overlap between the mean F0 values for the three tone levels. In fact, outside of the High Tense forms, which sometimes fall below Mid tone values late in the vowel, there is in fact no overlap between the means. However, though not overlapping, separation between the means was often quite narrow. For example, Low Lax tokens of Speaker B were less than $10 \mathrm{~Hz}$ lower than the Lax and Tense Mid tones in citation form and phrase-initial words (Figures $4 \mathrm{~b}$ and $4 \mathrm{c}$ ).

Generally, register had little effect on the F0 of Low and Mid tone items. That is, F0 in Lax syllables was similar to F0 in Tense syllables. A regular difference conditioned by register was between the High Lax and High Tense forms, the former rising or staying high even and the latter consistently realized as a fall. The late F0 values on the falling High Tense forms often fall below the Mid tone levels.

Regarding the effect of phrasal context, it is interesting that the clearest 3-way F0 contrast was found in the Phrase-medial condition, where a roughly $20 \mathrm{~Hz}$ separation was maintained between adjacent tone levels.

Statistical significance of F0 measures are given in Table 2, where each row displays the result of a separate regression test in which the occupied cells indicate the final regression model. Reference levels for each factor were: the M(id) tone for Tone; Lax for Register, and Phrase-medial for Frame. To demonstrate, for mean F0 as a DV, the model for Speaker A shows that:

- The Low tone as well as the High had a highly significant effect (***) on the mean F0 as differentiated from the mean Mid F0 level.

- The Tense register did not significantly alter F0 from the Lax reference level and was not included in the model.

- The Citation form utterances were significantly affected (**) from the Phrasemedial level, but Phrase-initial tokens were not. 


\begin{tabular}{|c|c|c|c|c|c|c|c|}
\hline \multirow[t]{2}{*}{ Dependent Variable } & \multicolumn{2}{|c|}{ Tone } & Register & \multicolumn{2}{|c|}{ Frame } & \multicolumn{2}{|c|}{ Interactions } \\
\hline & Sp.A & $\mathrm{B}$ & A $\quad$ B & A & B & A & $\mathrm{B}$ \\
\hline mean F0 & $\begin{array}{l}* * * \mathrm{~L}, \\
* * * \mathrm{H}\end{array}$ & $\begin{array}{l}* * * \mathrm{~L}, \\
* * * \mathrm{H}\end{array}$ & & $* *$ Cit & $* * *$ Cit & & \\
\hline F0 at $5^{\text {th }}$ decile & $\begin{array}{l}* * * \mathrm{~L}, \\
* * * \mathrm{H}\end{array}$ & $\begin{array}{l}* * * \mathrm{~L}, \\
* * * \mathrm{H}\end{array}$ & & $* *$ Cit & $* * * \mathrm{Cit}$ & & \\
\hline F0 at $8^{\text {th }}$ decile & $\begin{array}{r}* \mathrm{~L}, \\
* * * \mathrm{H}\end{array}$ & $\begin{array}{r}* \mathrm{~L}, \\
* * * \mathrm{H}\end{array}$ & & *Cit & ***Cit & *H:T & *H:T \\
\hline
\end{tabular}

Table 2. Regression tests for measures of F0

$$
* p<.05, * * p<.01, * * * p<.001
$$

As we might expect, Tone was a highly significant predictor of F0 - the mean F0 over the duration of the vowel as well as the F0 measured at various decile timepoints. Register, conversely, did not affect F0 except that there was an interaction for both speakers such that Tense tokens which were also High-toned had significantly lower F0 late in the vowel (the $80 \%$ decile). The effect of frame was such that Citation form utterances were significantly different from Phrase-medial forms. Looking to Figures 3-4, it can be seen that this effect is one of overall lower F0 values in the citation tokens.

4.3 MeAsures of Phonation. The array of measures distinguishing Lax from Tense register in Oeshi paint a much messier picture than does F0 for tone. Still, a loose pattern emerges wherein Tense tokens typically have lower values for each of the measures examined: H1-H2*, H1-A1*, H1-A3*, HNR 0-5k, HNR 3-5K, and SHR. Nevertheless, few of these differences were large enough or consistent enough to be statistically significant (see Tables 3, 4).

Interestingly, Tone was a decent predictor of $\mathrm{H} 1-\mathrm{H} 2 *$, patterned loosely such that the progression High $>$ Mid $>$ Low was progressively more constricted. This finding corresponds to the most consistent statistical finding for phonation - register as a predictor of $\mathrm{H} 1-\mathrm{H} 2 *$ on Low tones (and on High tones for just Speaker A). This effect is seen in the interactions in Table 3, interactions between tone and register that effectively indicate that there was a lack of a difference between Tense and Lax registers primarily on Mid tone forms. Although $\mathrm{H} 1-\mathrm{A} 3 *$ found a small significant effect of Tone for one speaker, our interpretation of these results is that $\mathrm{H} 1-\mathrm{H} 2 *$ was the most reliable metric of Oeshi register. Traces of mean $\mathrm{H} 1-\mathrm{H} 2 *$ over the vowel duration is given in Figures 5, 6 . 

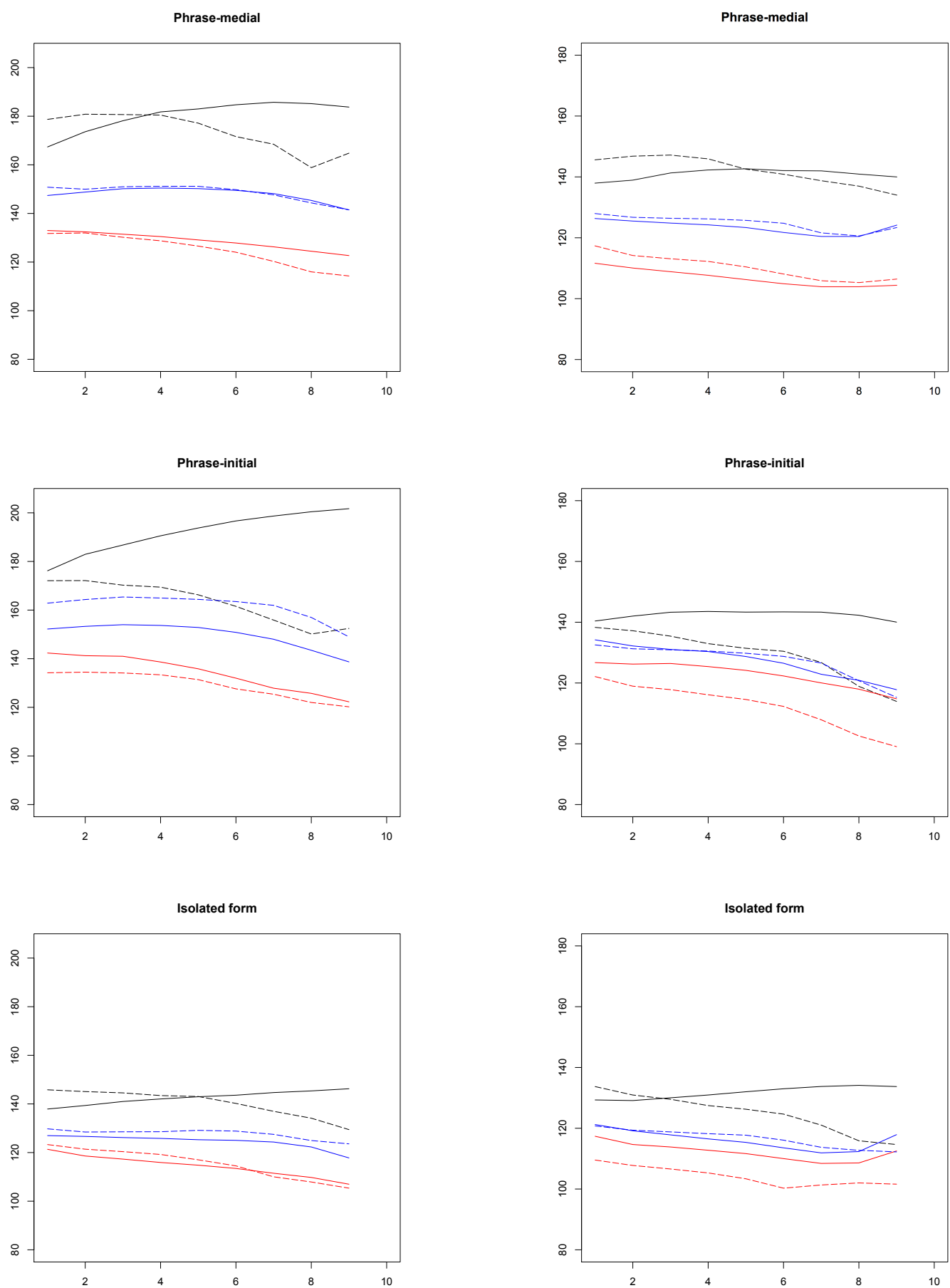

Figure 3. F0 for Speaker A Figure 4. F0 for Speaker B across 3 contexts

Low $=$ Mid -
Lax $\longrightarrow$ Tense - -
across 3 contexts 

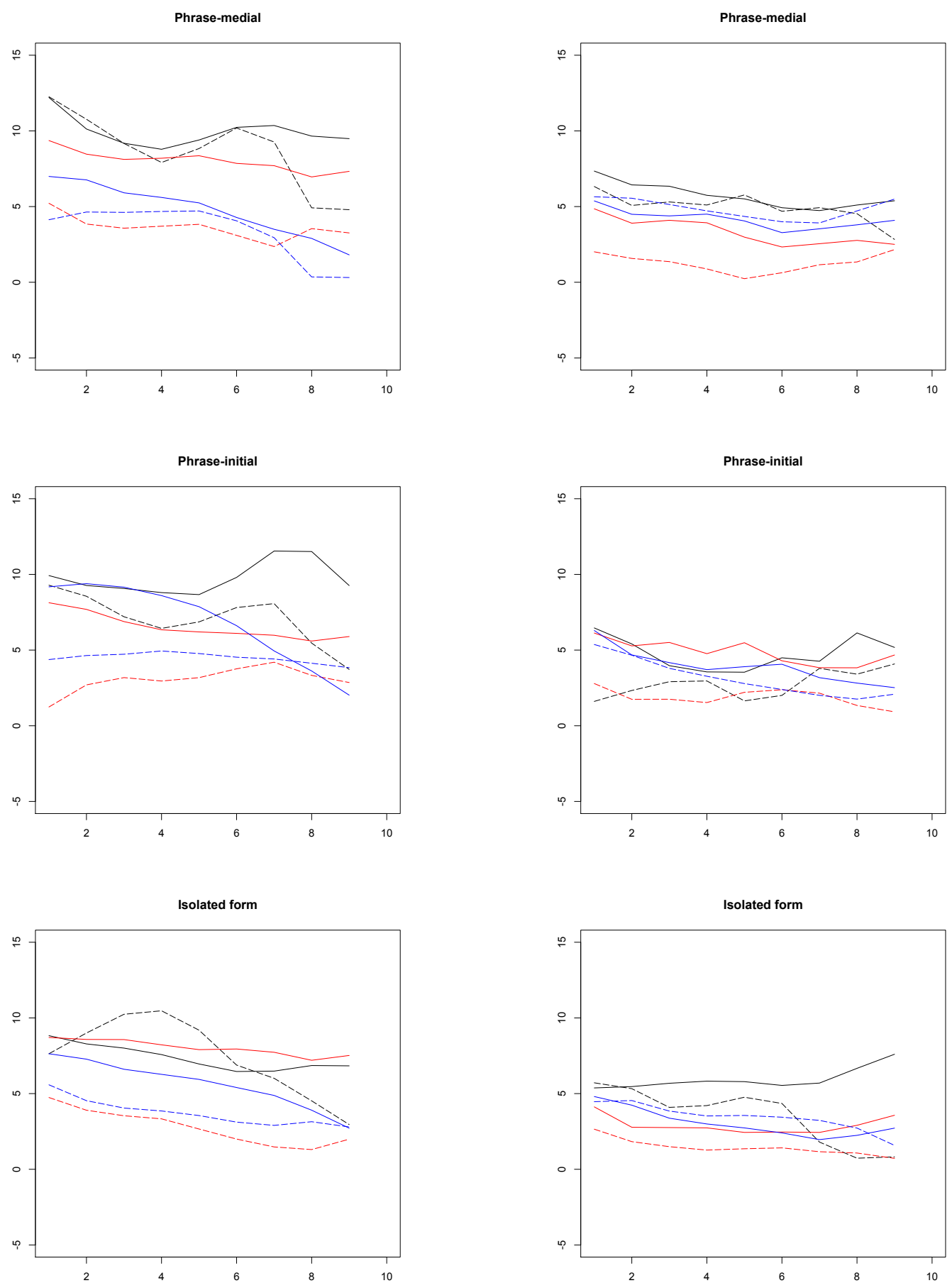

Figure 5. H1-H2* for Speaker A across 3 contexts

Low $=$ Mid $=$
Lax $=$ Tense - -

Figure 6. H1-H2* for Speaker B across 3 contexts 


\begin{tabular}{|c|c|c|c|c|c|c|c|}
\hline \multirow[t]{2}{*}{ Dependent Variable } & \multicolumn{2}{|c|}{ Tone } & Register & \multicolumn{2}{|c|}{ Frame } & \multicolumn{2}{|c|}{ Interactions } \\
\hline & Sp. A & $\mathrm{B}$ & A $B$ & $\mathrm{~A}$ & B & A & B \\
\hline mean $\mathrm{H} 1-\mathrm{H} 2 *$ & ${ }^{*} \mathrm{H}$ & $\begin{array}{r}* \mathrm{~L}, \\
* * \mathrm{H}\end{array}$ & & $* * \mathrm{C}$ & & $\begin{array}{r}* * \mathrm{~L}: \mathrm{T}, \\
* \mathrm{H}: \mathrm{T}\end{array}$ & ${ }^{*} \mathrm{~L}: \mathrm{T}$ \\
\hline $\mathrm{H} 1-\mathrm{H} 2 * 8^{\text {th }}$ decile & & $\begin{array}{r}* \mathrm{~L}, \\
* * * \mathrm{H}\end{array}$ & & $\begin{array}{l}* \text { Ini } \\
{ }^{*} \mathrm{C}\end{array}$ & & $\begin{array}{l}{ }^{*} \mathrm{~L}: \mathrm{T} \\
* * \mathrm{H}: \mathrm{T}\end{array}$ & ${ }^{*} \mathrm{~L}: \mathrm{T}$ \\
\hline \multicolumn{8}{|l|}{ mean H1-A1* } \\
\hline $\mathrm{H} 1-\mathrm{A} 1 * 8^{\text {th }}$ decile & ${ }^{*} \mathrm{H}$ & & & & & & \\
\hline mean $\mathrm{H} 1-\mathrm{A} 3 *$ & & & *T & & $*$ Cit & ${ }^{*} \mathrm{H}: \mathrm{T}$ & \\
\hline $\mathrm{H} 1-\mathrm{A} 3^{*} 8^{\text {th }}$ decile & & & $* \mathrm{~T}$ & & $*$ Cit & & \\
\hline
\end{tabular}

Table 3. Regression tests for measures of $\mathrm{H} 1-\mathrm{H} 2 *, \mathrm{H} 1-\mathrm{A} 1 *, \mathrm{H} 1-\mathrm{A} 3 *$

\begin{tabular}{|c|c|c|c|c|c|c|c|}
\hline \multirow[t]{2}{*}{ Dependent Variable } & \multicolumn{2}{|c|}{ Tone } & Register & \multicolumn{2}{|c|}{ Frame } & \multicolumn{2}{|c|}{ Interactions } \\
\hline & Sp. A & $\mathrm{B}$ & A $\quad$ B & $\mathrm{A}$ & $\mathrm{B}$ & $\mathrm{A}$ & $\mathrm{B}$ \\
\hline mean HNR 0-5k & $\begin{array}{l}* \mathrm{~L}, \\
* * \mathrm{H}\end{array}$ & $* * * \mathrm{~L}$ & $* \mathrm{~T}$ & & $\begin{array}{l}* * \text { Init, } \\
* * \text { Cit }\end{array}$ & & \\
\hline HNR $0-5 \mathrm{k} 8^{\text {th }}$ decile & $* * * \mathrm{H}$ & $\begin{array}{l}{ }^{*} \mathrm{~L}, \\
{ }^{*} \mathrm{H}\end{array}$ & $* * * \mathrm{~T}$ & & $\begin{array}{l}* * \text { Init } \\
* \text { Cit } \\
\end{array}$ & & $\begin{array}{l}{ }^{*} \mathrm{~L}: \mathrm{T}, \\
{ }^{*} \mathrm{H}: \mathrm{T}\end{array}$ \\
\hline mean HNR 3-5k & $* * * \mathrm{H}$ & & & & & $* * \mathrm{H}: \mathrm{T}$ & \\
\hline HNR $3-5 \mathrm{k} 8^{\text {th }}$ decile & $* * * \mathrm{H}$ & $* \mathrm{H}$ & & & & $* * * \mathrm{H}: \mathrm{T}$ & $\begin{array}{l}{ }^{*} \mathrm{~L}: \mathrm{T}, \\
{ }^{*} \mathrm{H}: \mathrm{T}\end{array}$ \\
\hline mean SHR & & & & & & & \\
\hline SHR at $8^{\text {th }}$ decile & $* * \mathrm{H}$ & & & & & ${ }^{*} \mathrm{H}: \mathrm{T}$ & \\
\hline
\end{tabular}

Table 4. Regression tests for measures of HNR 0-5k, HNR 3-5k, SHR

\section{DisCUSSION}

Analysis of the speech of two Oeshi men has shown that $\mathrm{F} 0$ is reliably distinct between each of the tones but that measures of phonation type less consistently distinguish the Lax and Tense registers. A poor recording environment and quality of the recordings may in some part serve as a confound to these measures. Other potential sources may be linguistic however.

For one, the articulatory basis of Oeshi lax or tenseness may simply not be reflected well by certain measures. In this case, the present study is hampered by a small sample size. More speakers producing more words may offer a fairer sense of the acoustic difference in Oeshi registers.

More enticingly, our impressionistic analysis of Oeshi speech (both in person and in the recordings) suggests that register behaves as a property of the syllable, being realized by one or more of the following laryngeal modifications: (i) aspiration/preglottalisation of the onset, (ii) non-modal voice quality on the vowel (often solely at the vowel terminus), or (iii) by a weak to full [h] or [?] coda.

While the present data face many limitations, they also offer a satisfying glimpse into the suprasegmental phonetics of a previously undescribed language. The analysis provides a novel datapoint in a typological arena of much recent interest in the literature 
- laryngeally complex tones with concomitant pitch and phonation properties. A quick cognate comparison with other Southern Ngwi languages (Hansson 1989) suggests that Oeshi, or Oeshi and Louma, indeed confirm Gregerson et al's (2011) suggestion to classify Oeshi (or perhaps Louma as an encompassing variety) as a distinct language. An example is the form for Proto-Lolo *wàk 'pig'. Sila and Oeshi retain onset and final constriction in /wà̀/, Akha and most Hani varieties are/ya/. Similarly, 'iron' /cén/ looks

more like Mpi /sig 5 / than Akha /sjhḿ/ or Hani/só/. In the context of similar mixed pitchphonation systems in SE Asia, the possible typological status of this language variety suggest implications for models of historical reconstruction, tonogenesis and registrogenesis.

Many citation forms contain a final glottal stop, which is not present in utterancemedial position. The conflicting readings for final glottal constriction may go back to either emphasis, or to a particular affix if uninflected forms are prohibited by Oeshi phonotactics. This requires further investigation of the Oeshi phonological-syntactic interface, especially since grammaticalization of tone and phonation is common for Tibeto-Burman languages and has been observed for the related Southern Ngwi language Akha (Hansson 2003). The phonatory alternation may go back to a form of affixation, further supporting that Tibeto-Burman languages are not strict morphologically isolating (Brunelle \& Kirby 2016).

The rare but present occurrences of the High Tense tone invite a closer crosslinguistic look at possible mechanisms for either development or loss of High Tense tone in Southern Ngwi languages. Whereas modern Tibeto-Burman languages usually employ mixed pitch-phonation system (à la Burmese, see Gruber 2011), the intersection of tone and phonation possibly points at an older stage of tone- and registrogenesis preserved in Oeshi.

The manifestation of laryngeal constriction in Oeshi at the onset, the kernel, and in coda position makes a look at underlying proto forms worthwhile. An attested form with both initial and final glottal constrictions ['gù?] 'rice grain' was reconstructed as * ?gaw for Proto-Lolo (Bradley 1977b). A detailed comparison of the locality of glottal constriction in Oeshi with that of oral or glottal closure points in Proto-Lolo or ProtoTibeto-Burman may provide further insight on the development of tone and phonation in Southern Lolo/Ngwi in particular and Tibeto-Burman in general.

\section{References}

Abramson, Arthur S., and Theraphan Luangthongkum. 2009. A fuzzy boundary between tone languages and voice-register languages. Frontiers in Phonetics and Speech Science, 149-155.

Berkson, Kelly. 2013. Phonation types in Marathi: An acoustic investigation. Lawrence, KS: University of Kansas dissertation.

Boersma, Paul \& Weenink, David. 2015. Praat: doing phonetics by computer [Computer program]. Version 5.4.07, retrieved 22 March 2015 from http://www.praat.org/

Bradley, David. 1977a. Akha and Southern Loloish. Pacific Linguistics 49.5, 23-65.

Bradley, David. 1977b. Proto-Loloish tones. Papers in SE Asian Linguistics 5, 1-22. 
Bradley, David. 1996. Tibeto-Burman languages of PDR Lao. Linguistics of the TibetoBurman Area 19.1, 19-27.

Brunelle, Marc. 2005. Register in eastern Cham: Phonological, phonetic and sociolinguistic approaches. Ithaca, NY: Cornell University dissertation.

Brunelle, Marc \& Kirby, James. 2016. Tone and Phonation in Southeast Asian Languages. Language and Linguistics Compass 10.4, 191-207. http://dx.doi.org/10.1111/lnc3.12182

Clements, G. Nick, Michaud, Alexis \& Patin, Cédric. 2011. Do we need tone features? In: Hume, Elizabeth; Goldsmith, John; Wetzels, Leo. Tones and features. Berlin/Boston: De Gruyter Mouton, 3-24.

DiCanio, Christian T. 2009. The phonetics of register in Takhian Thong Chong. Journal of the IPA 39, 162-176. http://dx.doi.org/10.1017/S0025100309003879

DiCanio, Christian T. 2010. Itunyoso Trique. Journal of the International Phonetic Association 40.2, 227-238. http://dx.doi.org/10.1017/S0025100310000034

DiCanio, Christian T. 2012. Coarticulation between tone and glottal consonants in Itunyoso Trique. Journal of Phonetics 40.1, 162-176. http://dx.doi.org/10.1016/j.wocn.2011.10.006

Esposito, Christina M. 2006. The effects of linguistic experience on the perception of phonation. Los Angeles, CA: UCLA dissertation.

Esposito, Christina M. 2012. An acoustic and electroglottographic study of White Hmong tone and phonation." Journal of Phonetics 40.3, 466-476. http://dx.doi.org/10.1016/j.wocn.2012.02.007

Gregerson, Kenneth, Gregerson, Marilyn \& Vitikainen, Ari. 2011. Workshop on Rshi (Akha) language and culture. Unpublished report. CRWRC: Muang Mai, Phongsali, Lao PDR.

Gruber, James. 2011. An articulatory, acoustic, and auditory study of Burmese tone. Washington, D.C.: Georgetown University dissertation.

Hansson, Inga-Lill. 1989. A Comparison of Akha, Hani, Khàtú and Pîjò. Linguistics of the Tibeto-Burman Area 12:1, 6-91.

Hansson, Inga-Lill. 2003. Akha. In: Graham Thurgood \& Randy J. LaPolla (eds). The Sino-Tibetan Languages. London/New Youk: Routledge, 236-251.

Katsura, Makio. 1970. An Outline of the Structure of the Akha Language. Southeast Asian Studies 8.1, 16-35

Khan, Sameer ud Dowla. 2012. The phonetics of contrastive phonation in Gujarati. Journal of Phonetics 40, 780-795. http://dx.doi.org/10.1016/j.wocn.2012.07.001

Kirby, James. 2014. Incipient tonogenesis in Phnom Penh Khmer: acoustic and perceptual studies. Journal of Phonetics 43, 69-85. http://dx.doi.org/10.1016/j.wocn.2014.02.001

Kuang, Jianjing. 2013. Phonation in Tonal Contrasts. Ph.D. Dissertation, UCLA. 
Lewis, Paul. 1973. Tone in the Akha language. Anthropological Linguistics 10:2, 8-18.

Potter, Margaret. 2012. Rapid appraisal survey in the Rshi area: data analysis. Unpublished manuscript. Chiang Mai, Thailand: Unpublished manuscript.

R Core Team. 2012. R: A language and environment for statistical computing. $\mathrm{R}$ Foundation for Statistical Computing, Vienna, Austria. ISBN 3-900051-07-0, URL http://www.R-project.org/

Shue, Yen-Liang, Keating, Patricia, Vicenik, Chad, and Yu, Kristine. 2011. Voicesauce: a program for voice analysis. In Proceedings of the ICPhS XVII, 1846-1849.

Silverman, Daniel. 1997. Laryngeal complexity in Otamanguean vowels. Phonology 14, 235-261.

Yu, Kristine M. \& Lam, Hiu Wai. 2014. The role of creaky voice in Cantonese tonal perception. The Journal of the Acoustical Society of America 136.3, 1320-1333. http://dx.doi.org/10.1121/1.4887462 